\title{
Conceptual framework of STEM based on Japanese subject principles
}

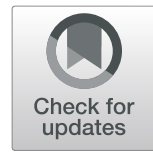

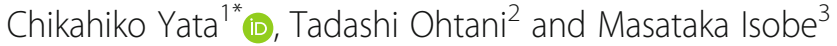

\begin{abstract}
Background: School education should improve science, technology, engineering, and mathematics (STEM) ability not only in science and mathematics but also in technology and engineering. However, practice and research are being conducted without clear definitions and methods for STEM education. Moreover, the positioning and characteristics of the technology included in each STEM field are unclear. Therefore, it is necessary to propose an appropriate framework for practice of STEM from the viewpoint of technology education. In response to this need, this commentary proposes a conceptual framework for the appropriate practice of STEM education.

Results: First, we referred to the perspectives and thinking styles of the fields of science, technology, and mathematics in the Japanese curriculum to specify the approach of the education system to each subject included in STEM. Next, to determine the concept of engineering in STEM education, we referred to the definition of engineering presented in Japan, the USA, and the UK. We positioned engineering, which means creating structures, processes, systems, etc., as a practical STEM activity and attempted to relate it to the unique perspectives and thinking styles of mathematics, science, and technology.

Conclusion: We proposed a conceptual framework for the appropriate practice of STEM education based on the principles of subjects in the Japanese curriculum. The conceptual framework suggests that a means to improve the practice of STEM education is to retain the principles of science, technology, and mathematics in the activity of engineering. It can be inferred that the key point for practicing STEM education is to examine and design the appropriate order and combination of the learning process and activities based on the proposed conceptual framework. Although this framework is theoretical, it can be useful in determining an adequate practice of STEM education and clarifying the relationship between STEM education and technology education.
\end{abstract}

Keywords: Conceptual framework, STEM, Japanese curriculum, Subject principles, Design process, Engineering

\section{Introduction}

\section{STEM education worldwide}

Science, technology, engineering, and mathematics (STEM) have been promoted as an educational reform project on a national scale in Europe, the USA, and elsewhere. STEM education aims at enhancing the workforce related to the STEM field and nurturing STEM

\footnotetext{
* Correspondence: cyata@hiroshima-u.ac.jp

'Department of Technology and Information Education, Graduate School of Education, Hiroshima University, 1-1, Kagamiyama 1-chome, Higashi-, Hiroshima, Japan

Full list of author information is available at the end of the article
}

literacy in order to address the major challenges of the twenty-first century (Bybee, 2010).

In the USA, a report from the Committee on STEM Education, National Science and Technology Council (2013) indicated that to maintain American superiority in innovation, it would be necessary to ensure that the STEM workforce has excellent skills and training. In the UK, the Royal Society (2016) issued a guidebook called "Making education your business" to support companies in teaching STEM education to promote employment and increase interest in the STEM field. Integrated education in the STEM education system in K-12 schools needs to be improved as a national policy to ensure that 
the future generation possesses adequate skills to work in these fields.

Furthermore, STEM education is also required to foster skills such as problem-solving and nurturing literacy in each STEM subject (Bybee, 2010). The literacy cultivated through STEM education can develop an individual's decision-making ability, enabling them to understand and address various real-world problems. It is thought that STEM learning activity will cultivate skills such as creativity, critical thinking, problemsolving, and decision-making, while problems related to the humanities such as politics, economics, and society can also be considered to be linked to STEM knowledge (Banks \& Barlex, 2014; Daugherty, 2009). Daugherty indicated the potential of STEM education "to prepare the next generation of students with enhanced skills to solve complex problems, consider consequences, think critically, collaborate across disciplinary boundaries, invent and innovate, and compete with the best the world has to offer." Banks and Barlex suggested that in the UK, the emphasis in STEM education is on understanding the relationship between STEM and daily life, society, and decision-making for creative problem-solving. Therefore, when STEM education is implemented in each of the STEM subjects, it is necessary to develop STEM knowledge and skills in relation to the other subjects, in addition to learning each subject separately.

STEM education emphasizes activities to design and create new products and systems as well as activities related to the principles of inquiry and exploration. Through both approaches, STEM education can help students to acquire and utilize knowledge and skills related to the STEM field, to learn the practices of scientists and engineers in the real world, and to think about problem-solving.

\section{Concept of STEM and technology education}

Kelley and Knowles (2016) suggested that educators and schools lack a cohesive understanding of the practice of STEM education. They pointed out that teachers need to use deliberate methods to teach STEM content that foster students' understanding of how to learn STEM and solve real-world problems. To this end, they emphasized that building a strategy to integrate STEM concepts requires a strong conceptual and foundational understanding of how students learn and apply STEM content. Brown, Ernst, DeLuca, and Kelly (2017) noted that STEM education is a current educational issue that is not always consistently defined. They describe STEM education as a course, unit, or lesson that integrates two or more STEM areas and presents an integrated approach to teaching and learning, where discipline-specific content is not divided but is addressed and treated as a single dynamic. Although these studies point out the problem of the lack of clear and consistent definition in STEM education, they do not attempt to provide one.

McGarr and Lynch (2017) also found that while there is an acceptance among stakeholders that a focus on STEM is important in supporting the global competitiveness of the USA, there is "no common operational definition or conceptualization of STEM." In addition, the Royal Society (2016) tried to promote corporate cooperation in the implementation of STEM education but did not clarify what its contents and methods should be. As a result, there is a general concern that STEM education practiced under various motivations and definitions will further obscure its contents and methods.

Furthermore, there is a tendency for STEM education to be discussed by educators and researchers mainly from the standpoint of science and mathematics. The necessity of increasing the focus on technology and engineering in education has been pointed out (Daugherty, 2009; Successful STEM Education, 2013). Another fact that complicates the overall definition of STEM education is the different nature of subject curricula in different countries. Therefore, it may be necessary to develop a curriculum for STEM education according to the characteristics of the relevant subject in each country.

From the viewpoint of technology education, Havice (2009) noted that STEM education is a key pathway to technological literacy. Havice also appealed to the capacity of hands-on technology and engineering education to bring the real world into the classroom, allowing students to analyze problems, issues, and trends and to respond to challenges with adaptability and flexibility. Sanders (2009) explained the importance of establishing a comprehensive and effective relationship with the objectives, content, and methods required for each STEM subject. On the other hand, Reed (2018) emphasized that technology education must maintain a relevant identity as a STEM discipline and must also continue to be built on the pillars that define the discipline in terms of content: an epistemological basis and a history of practice that is inclusive of curriculum, teaching, and research. Reed also warned that technology educators should not focus too much on STEM education or divert attention from the mission of technology education.

As shown above, both the definition and positioning of STEM education are ambiguous, and its contents, methods, and concepts are unclear. In addition, there is a bias towards science and mathematics at the expense of technology and engineering. STEM education is characterized by having both creative and exploratory learning activities. In terms of creative learning activities, it is necessary to promote STEM education practice and research from the viewpoint of technology and engineering. To that end, several learning models that can be helpful to the practice of STEM education related to technology education are outlined below. 
STEM education model and technology education The relationship between technology and other subjects and fields has been noted by the International Technology Education Association (ITEA, 2005), which became the International Technology and Engineering Educators Association (ITEEA) in 2010. The relationship with science is still under consideration in the process of thinking about the design and development of technology and engineering. Johns and Mentzer (2016) noted the relevance of practice and activity for both engineering design and scientific inquiry, seen in activities such as "planning and carrying out investigations," "analyzing and interpreting data," "engaging in argument from communicating information," and "obtaining, evaluating, and communicating information." These shared activities suggest that scientific inquiry can be included in the steps of the design process, during activities such as research and data analysis.

The previous studies described below have attempted to develop a curriculum for science and technology education focused on the engineering process and scientific inquiry. These factors can be applied as an approach to STEM education, and studies have been conducted on various learning models.

The 6E Learning byDeSIGN ${ }^{\mathrm{m}}$ Model is a framework for instruction that leverages STEM technology and engineering (Barry, 2014; ITEEA, 2015). This model is based on the Biological Sciences Curriculum Study's (BSCS) 5E Instructional Model (Bybee, Taylor, et al., 2006). The ITEEA (2012) developed EbD-TEEMS ${ }^{\text {mix }}$ for the elementary curriculum, which is a model and teaching resource designed to help teachers provide a meaningful foundation in STEM education. For example, "Agriculture Around Us" (ITEEA, 2012) is a unit for first graders. Lessons using the BSCS 5E Instructional Model can be planned and practiced using the framework of Engage, Explore, Explain, Elaborate, and Evaluate. However, the BSCS 5E Instructional Model was noted to be problematic as it did not fully elaborate the design process. In addition, the need for a learning model combining engineering design and scientific inquiry has increased. The $6 \mathrm{E}$ Learning byDeSIGN ${ }^{\mathrm{m}}$ Model was created by adapting the BSCS 5E Instructional Model to make it more related to engineering design. This model is also related to mathematical modeling. The ITEEA (2016) also introduced the teaching tool "Our World and $\mathrm{Me}$ " for the sixth-grade elementary school curriculum, which comprises three units using the framework of Engage, Explore, Explain, Engineer, Enrich, and Evaluate as a sequential lesson structure.

In the simplified version of the model shown in Fig. 1, the relationship between engineering design and scientific inquiry can be interpreted as a one-way system.

As an example of a learning or instruction model based on subjects, such as a design model for technology and engineering, the BSCS model (Bybee, 1997), based on science, is strongly related to the content and activities of individual subjects. With lessons that use the BSCS model (Bybee, 1997), there is a tendency to provide subject-based teaching and evaluation. By contrast, Wells (2016) presented the PIRPOSAL model, which was developed as an approach to STEM education that is not based on the individual subject framework.

As shown in Fig. 2 below, the center of the PIRPOSAL model is Questioning, with the phases (drawn on the outside) comprising Problem Identification, Ideation, Research, Potential Solution, Optimization, Solution Evaluation, Alterations, and Learned Outcomes. Each phase is associated with Questioning as indicated by the double-headed arrow, and the phases represent how engineers think and act in relation to technological problem-solving. The phases are not ordered but are positioned in activities relative to inner Questioning, which is the departure point of learning. That is, the teacher grasps the correspondence between a given phase and Questioning and judges how to teach and provide instruction accordingly. Thus, Questioning plays a role in terms of clarifying what knowledge is necessary to proceed with the process. There are two thinking styles of Questioning: the "convergent thinking" style means accessing facts and verifiable information, while "divergent thinking" refers to inquiry through open-ended questions without a single correct answer.

In the simplified version of this model shown in Fig. 2, the relationship between engineering design and scientific inquiry can be interpreted as a dynamic, interrelated, two-way activity.

In science education, design learning environments have been found to promote deep learning of science content and practices. Kolodner (2002) presented Learning by

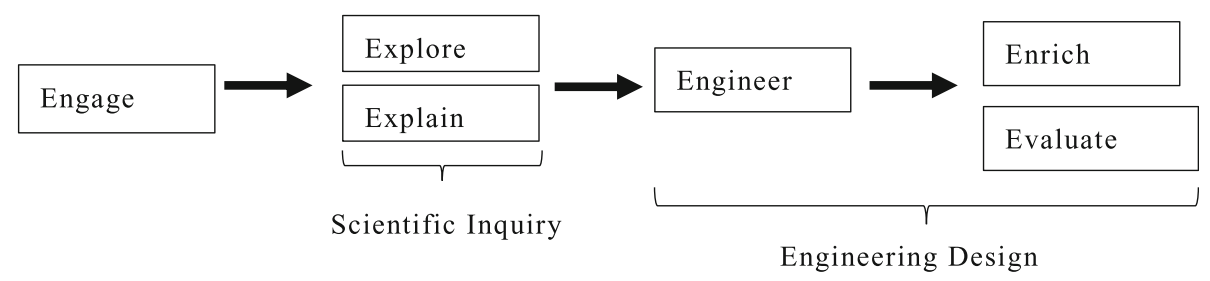

Fig. 1 The 6E Learning byDeSIGN'M Model simplified by the authors with reference to ITEEA (2016) 


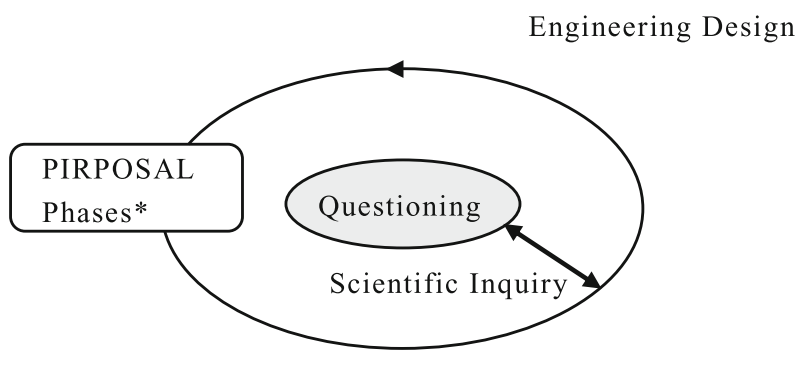

*PIRPOSAL phases comprise Problem Identification, Ideation,

Research, Potential Solution, Optimization, Solution Evaluation,

Alterations, and Learned Outcomes.

Fig. 2 PIRPOSAL model simplified by the authors with reference to Wells (2016)

$\operatorname{Design}^{\mathrm{Tn}}$, which is a project-based inquiry approach to learning science contents and skills through hands-on experience by undertaking a design challenge. The Learning by Design ${ }^{\text {Tw }}$ cycle consists of two processes shown in parallel. One is the process of "design/redesign," and the other is the process of "investigate and explore." Learners engage in design challenges which create the need to investigate, and that investigation is engaged in whenever the need arises during the design process. The transition from "design/redesign" to "investigate and explore" is represented by an arrow labeled "need to know," while the transition from "investigate and explore" to "design/redesign" is represented by an arrow labeled "need to do." This way of thinking is helpful in considering the mutual relevance of the processes of engineering and science.

In the simplified version of this model shown in Fig. 3, the relationship between engineering design and scientific inquiry can be interpreted as different activities linked by the needs to "know" and "do."

Each model described above considers the relation between scientific inquiry and the process of engineering design. However, it is unclear how each model incorporates the unique contents, methods, and concepts of mathematics, science, and technology and their involvement in the engineering process. ITEEA (2018) presented three principles to drive STEM education in "STEM4: The power of collaboration for change." The principles for STEM education should "advance the learning of each individual STEM discipline" and "STEM education should provide logical and authentic connections between and across the individual STEM disciplines." The report also highlighted the importance of a learning policy that emphasizes the discipline of each subject and how it relates to STEM. In planning and implementing STEM education, it is necessary to respect the content, method, and concepts of the individual subjects and to consider the necessity and importance of building relationships between them.

\section{Understanding STEM education in Japan}

In Japan, it is difficult to say that there is an accepted institutional consensus on the theory of the content and methodology of STEM education. While relationships between STEM education and mathematics and science are considered, there seems to be no strong intention to conceive a formal school curriculum in Japan that includes learning content and methods based on the concepts of STEM education. On the other hand, in informal education in Japan, STEM education practice is being promoted without a clear definition of its contents and methods. For example, in cram schools and public lectures, there have been examples of STEM education dealing with the manufacturing of robots, programming for measurement and control, and digital fabrication. However, these contents and activities

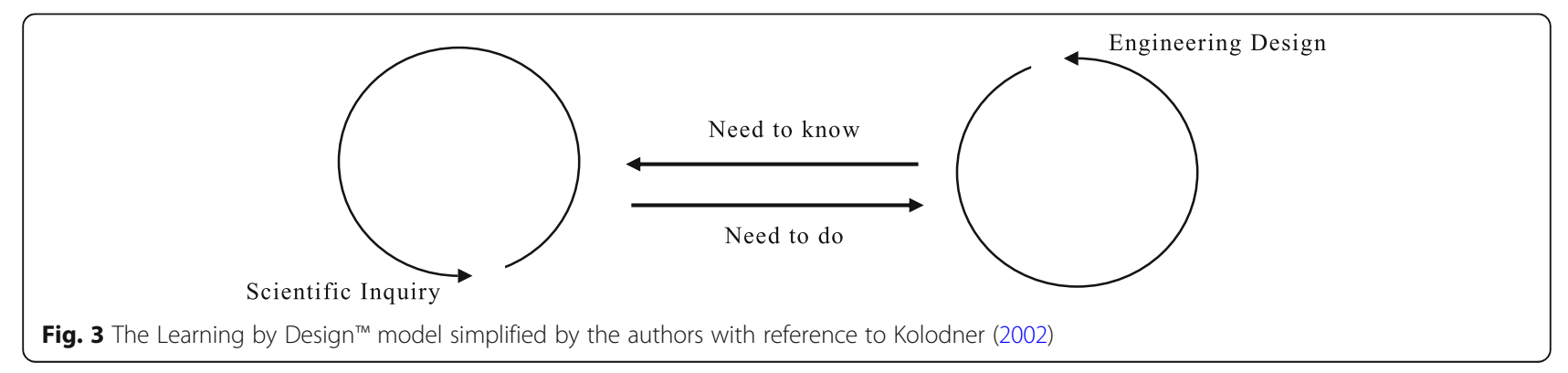


are very close to the learning activities of technology education, and they are not planned and implemented under the clear provision of a STEM education framework. In this light, it is necessary to fully establish the identity and character of technology and engineering in STEM education (Harrison, 2011).

Considering STEM education in Japan from an international perspective, Ritz and Fan (2015) reported the perceptions of 20 international technology education scholars on their country's involvement in STEM education, and the following was pointed out in relation to Japanese STEM education: "Japan is experimenting with a version of STEM by bringing the abacus (soroban) back into schools for helping grade 3-4 students to strengthen their learning of mathematics and better understand its key operations." However, most Japanese educators do not consider learning the abacus in mathematics to be part of STEM education. This is a serious error and creates a major misunderstanding regarding Japanese education. To solve such misunderstandings, it is necessary to consider and propose the planning and implementation of STEM education based on the current situation of Japanese technology education.

\section{The purpose of this commentary}

In STEM education, there is no clear definition of the goals, methods, and contents of abilities related to STEM subjects. Such definitions are necessary to promote well-understood practices and enhance students' abilities. In addition, when STEM education is implemented in different countries, the particular characteristics of the subjects in that country's curriculum are related to the outcomes of STEM education. Therefore, it is useful to construct a conceptual framework that takes into account the characteristics and perspectives of each subject to enable the planning and implementation of STEM education. Of the learning activities in STEM education, many studies have been conducted on science and mathematics, which mainly involve exploration. However, there is a lack of studies from the standpoint of technology and engineering, which are mainly creative learning activities (Daugherty, 2009; Successful STEM Education, 2013). Therefore, it is important to create a conceptual framework that incorporates the characteristics of science, mathematics, and engineering from the viewpoint of technology education.

In this commentary, we propose a conceptual framework for STEM education, based on the characteristics of the relevant subjects in Japanese education, and ask what contents learners can learn and what activities learners will be able to do by examining the concept of engineering in relation to the teaching of Japanese subjects. Based on the new course of study in Japan, we will discuss how science, mathematics, and engineering should be positioned in the proper planning and implementation of STEM education, with a focus on technology education. Through this examination, we aim to propose an improved method of implementing STEM education that fosters comprehensive literacy. This proposal will be useful to not only help build an effective STEM education practice but also to clarify the relationship between STEM education and technology education.

\section{The Japanese education system and technology education}

Qualities and abilities in Japanese education

First, we referred to the perspectives and thinking styles of the fields of science, technology, and mathematics in the Japanese curriculum to specify the education system's approach to each subject. In 2017, the Japanese Ministry of Education, Culture, Sports, Science and Technology (2017) devised a new course of study, meaning an outline standard of the elementary and middle school curricula, which was revised based on the global trend toward the development of generic skills and competencies. The qualities and abilities that the new course of study aims to nurture throughout the school curriculum are categorized as "knowledge and skills," "thinking, judgment, expression ability, etc.," and "ability to make use of learning, etc."

"Perspectives and thinking styles" in Japanese education MEXT outlines "perspectives and thinking styles" according to the characteristics of each subject with the intention that students should systematically acquire those qualities and abilities. It also prescribes "perspectives and thinking styles" as perceptions and ways of thinking that allow students to assimilate elements unique to each subject. This is considered important for the learning of new "knowledge and skills" that are useful in the real world, while associating them with existing "knowledge and skills." In addition, "perspectives and thinking styles" can enrich "thinking, judgment, and expression ability" and form an understanding of how this ability relates to society (Ministry of Education, Culture, Sports, Science and Technology, 2017).

In the new course of study, "perspectives and thinking styles" is positioned as the core of learning for each subject and is intended to connect the learning of various subjects to society. In junior high school, "perspectives and thinking styles" for technology, science, and mathematics are defined as shown in Table 1.

Technological "perspectives and thinking styles" comprise "understanding phenomena in daily life and society from the viewpoint of their relationship with technology and to think about optimizing technology focusing on social demand, safety, environmental burden, economic efficiency, etc." (Ministry of Education, Culture, Sports, 
Table 1 "Perspectives and thinking styles" of technology, science, and mathematics

\begin{tabular}{|c|c|c|}
\hline Subject & Perspective & Thinking style \\
\hline $\begin{array}{l}\text { Technology (Ministry } \\
\text { of Education, Culture, } \\
\text { Sports, Science and } \\
\text { Technology, 2018a) }\end{array}$ & $\begin{array}{l}\text { Focusing on social } \\
\text { demand, safety, } \\
\text { environmental } \\
\text { burden, economic } \\
\text { efficiency, etc. }\end{array}$ & $\begin{array}{l}\text { Thinking to } \\
\text { optimize/ } \\
\text { systematize }\end{array}$ \\
\hline $\begin{array}{l}\text { Science (Ministry of } \\
\text { Education, Culture, } \\
\text { Sports, Science and } \\
\text { Technology, 2018b) }\end{array}$ & $\begin{array}{l}\text { Focusing on } \\
\text { relationships as } \\
\text { qualitative/quantitative } \\
\text { and temporal/spatial }\end{array}$ & $\begin{array}{l}\text { Thinking to } \\
\text { explore theory/ } \\
\text { laws }\end{array}$ \\
\hline $\begin{array}{l}\text { Mathematics (Ministry } \\
\text { of Education, Culture, } \\
\text { Sports, Science and } \\
\text { Technology, 2018c) }\end{array}$ & $\begin{array}{l}\text { Focusing on quantities, } \\
\text { figures, and their } \\
\text { relationships }\end{array}$ & $\begin{array}{l}\text { Thinking with } \\
\text { numbers/symbols }\end{array}$ \\
\hline
\end{tabular}

Note: The references Ministry of Education, Culture, Sports, Science and Technology (2018a, 2018b, 2018c) are explanations of the courses of study for technology, science, and mathematics education. The table was created by interpreting and abbreviating the descriptions in these references

Science and Technology, 2018a). This definition is interpreted as emphasizing optimization in making products and systems, and optimization/systematization are considered characteristics of technological learning activity.

Scientific "perspectives and thinking styles" include "understanding of the natural world and phenomena from a scientific point of view, considering relationships such as qualitative/quantitative and temporal/spatial, and thinking about using scientific inquiry methods such as comparing and relating" (Ministry of Education, Culture, Sports, Science and Technology, 2018b). This definition is interpreted as emphasizing inquiry into scientific theories and laws by considering the natural world and phenomena. Thinking during inquiry also means exploring theories/laws as a characteristic of scientific learning activity.

The aims of mathematical "perspectives and thinking styles" are "to understand phenomena focusing attention on quantities, figures and their relationships, and to think logically, integratedly, and developmentally" (Ministry of Education, Culture, Sports, Science and Technology, 2018c). This definition is interpreted as emphasizing thinking through numbers and symbols. Logical thinking using numbers and symbols is considered a characteristic of mathematical learning activity.

\section{Engineering education in Japan}

In Japan, engineering is not established as a distinct subject in compulsory education and exists solely as a disciplinary area of specialized and higher education. Therefore, there is no real common concept of engineering. Nevertheless, it is adopted in the learning process in technology education. Even in science, manufacturing is incorporated as an activity of utilization and confirmation of theories and laws. In mathematics, mathematical modeling, which is regarded as a design-related activity, is researched and practiced. Thus, it seems that the framework of STEM education can be considered by examining each subject's relationship with engineering.

\section{Definition of engineering by country}

Next, to determine the concept of engineering in STEM education, we referred to the definition of engineering presented in Japan, the USA, and the UK.

Reed (2018) noted that engineering has been well defined at the postsecondary level but is still evolving in PreK-12 education in the USA. The way engineering is understood is important for considering STEM education, as there is no subject specifically titled "engineering" in elementary or secondary education in Japan.

The Review Committee on Educational Programs in Engineering (1998) defined engineering as "an academic discipline aimed at building useful things and comfortable environments for public safety, health, and welfare that is based on mathematics and natural sciences, sometimes using knowledge of humanities and social sciences."

The Engineering Academy of Japan (2006) noted that, in Japan, the way in which engineering is conceived is unique. Many Japanese universities have faculties of engineering, and engineering is commonly recognized as an academic discipline.

The ITEA (2000) presented a report titled "Standards for Technological Literacy: Content for the Study of Technology," where engineering is defined as follows:

The profession of or work performed by an engineer. Engineering involves the knowledge of the mathematical and natural sciences (biological and physical) gained by study, experience, and practice that are applied with judgment and creativity to develop ways to utilize the materials and forces of nature for the benefit of mankind.

For the first time in 2014, in its survey of academic achievement, the National Assessment of Educational Progress (NAEP) included "technology and engineering literacy" as one of its objectives. The NAEP defined engineering as "a systematic and often iterative approach to designing objects, processes, and systems to meet human needs and wants" (National Assessment Governing Board, 2013). These definitions highlight the engineering design process such as the activities applied to create things and systems.

In the USA, the National Academy of Engineering (2008) defines engineering as follows:

No profession unleashes the spirit of innovation like engineering. From research to real-world applications, engineers constantly discover how to improve our lives by creating bold new solutions that connect 
science to life in unexpected, forward-thinking ways. Few professions turn so many ideas into so many realities. Few have such a direct and positive effect on people's everyday lives. We are counting on engineers and their imaginations to help us meet the needs of the 21 st century.

In this definition, engineering is considered as a profession and is also seen as an activity for creating something useful from ideas.

In the UK, the Royal Academy of Engineering (Malpas, 2000) defined engineering as follows:

The knowledge required, and the process applied, to conceive, design, make, build, operate, sustain, recycle or retire, something of significant technical content for a specified purpose; - a concept, a model, a product, a device, a process, a system, a technology.

In this definition, engineering is regarded as the knowledge and process related to specific technical content.

Table 2 summarizes the various definitions of engineering, which range widely to include scholarship, professions, activities, knowledge, etc., and shows that they are defined from various aspects. For example, reports from the Review Committee on Educational Programs in Engineering (1998) and the Engineering Academy of Japan (2006) regard engineering and its scope as an academic field.

In "Standards for Technological Literacy: Content for the Study of Technology" (ITEA, 2000) and National Academy of Engineering (2008), engineering is considered a profession. NAEP's definition of engineering as a "systematic and often iterative approach" matches well with the creative activities included in STEM (National Assessment Governing Board, 2013). Currently, engineering in STEM education can be assumed to be a creative activity

Table 2 Definitions of engineering by each association

\begin{tabular}{ll}
\hline Association & Definition of engineering \\
\hline $\begin{array}{l}\text { Review Committee on } \\
\text { Educational Programs in } \\
\text { Engineering (1998) }\end{array}$ & Academic discipline \\
$\begin{array}{l}\text { Engineering Academy of } \\
\text { Japan (2006) }\end{array}$ & Academic discipline \\
"Standards for Technological & $\begin{array}{l}\text { The profession of or } \\
\text { Literacy: Content for Study } \\
\text { of Technology" (ITEA, 2000) }\end{array}$ \\
"Technology and Engineering & an engineer \\
Literacy" (National Assessment & Systematic and often \\
Governing Board, 2013) & iterative approach \\
National Academy of & \\
Engineering (2008) & Profession \\
The Royal Academy of Engineering & \\
(Malpas, 2000) & Knowledge and process \\
\hline
\end{tabular}

based on a "systematic and often iterative approach," which is used in the design process, for example.

James Dyson, who was involved in the development of the curriculum for "Design and Technology," a subject in the UK's national curriculum, recommends that the design process be emphasized as an educational activity. The James Dyson Foundation (2017) defines the design process as engineers using "knowledge of science, technology, engineering, math and creative thinking to solve problems. Engineers refer to the stages of the design process as: Specify, Plan, Design, Build, Test, Analyze. This process is iterative and non-linear." The main processes in Dyson's definition are considered to be Design, Build, and Test.

Based on these ideas, when conceiving the conceptual framework of STEM in this research, we regarded engineering as a design process, which is a creative activity, and assumed that the main steps in the design process are Design, Build, and Test. Given that similar learning processes were used in the development of STEM education (Boakes, 2019; Cook \& Bush, 2018), we thought it was appropriate to adopt the design process for our framework.

\section{A proposed STEM framework}

STEM education, which combines science, technology, engineering, and mathematics, has the ability to increase the potential and skills of children of the next generation (Bybee, 2010). However, the theoretical framework of STEM education is unclear (Kelley \& Knowles, 2016). From the viewpoint of technology education, it is important to clarify the difference between STEM education and technology education. The present commentary generated a framework for STEM education by combining the perspectives and thinking styles of mathematics, science, and technology from the Japanese curriculum with the concept of engineering as defined by Japan, the USA, and the UK.

When interpreting engineering as work or activity, it is regarded as having a close relationship with technology education, such as in the subject "Design and Technology" in the UK. Engineering activities are dealt with in the same way in Japan and the UK because engineering contents and ways of thinking are not defined as specific subjects in either country. By referring to the PIRPOSAL and Learning by Design ${ }^{\text {Tx }}$ models, the thinking styles of each subject are conceived as the activities and requirements related to engineering.

We positioned engineering, which means creating things, processes, systems, etc., as a practical STEM activity and attempted to relate it to the unique perspectives and thinking styles of mathematics, science, and technology subjects in the Japanese course of study.

Figure 4 shows the design process (repeating the steps Design, Build, and Test) and unique perspectives and 
Activity of "engineering"

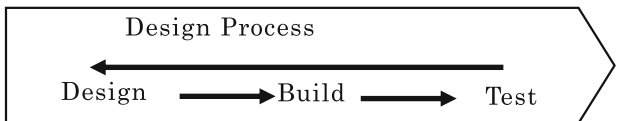

Need to know
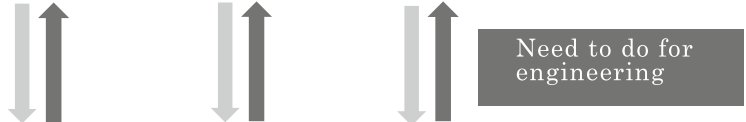

$\begin{array}{lll}\begin{array}{l}\text { Science } \\ \text { thinking to } \\ \text { explore } \\ \text { theory/law }\end{array} & \begin{array}{l}\text { Technology } \\ \text { thinking to } \\ \text { optimize/ } \\ \text { systematize }\end{array} & \begin{array}{l}\text { Mathematics } \\ \text { Thinking } \\ \text { nith } \\ \text { numbers/symbols }\end{array} \\ \text { Perspectives and thinking styles of each subject }\end{array}$

Fig. 4 Relationships between the engineering design process and science, technology, and mathematics

thinking styles of each subject (mathematics, science, and technology) in a multi-layered manner that is related to the context of "need to know" and "need to do for engineering." This framework organizes each STEM subject into activities and modes of thinking, demonstrating that the policy to promote STEM education through interdisciplinary cooperation assumes both the commonality and uniqueness of science, technology, engineering, and mathematics.

An example of "need to do for engineering" is that in the process of Design or Build, it is necessary to create products and systems using principles and theories related to factors such as materials, processes, and energy. In prototyping and modeling, knowledge and thinking styles are utilized to optimize materials and energy. As an example of "need to know," when the principles and theory to be utilized are insufficient, the necessity to acquire new knowledge arises.

Yet another example of "need to do for engineering" is that, in the process of Build or Test, it is necessary to inspect and measure various aspects of a prototype or model by using the perspectives and thinking styles of quantitative formulas and symbols. On the other hand, when it is not possible to appropriately represent various aspects of a prototype or model, the necessity of learning, which requires the knowledge and thinking style of mathematics etc., is an example of "need to know." Furthermore, when activities such as optimization are not proving to be effective, it becomes necessary to learn appropriate optimization processes and thinking in the context of "need to know."

In this way, when teaching the design process by repeating the steps Design, Build, and Test, the unique perspectives and thinking styles of mathematics, science, and technology contribute according to the context of "need to know" and "need to do for engineering." To facilitate the process of repeating the steps Design, Build, and Test to generate optimum products and systems, the unique perspectives and thinking styles of mathematics, science, and technology should be used functionally.

From the above, we consider that STEM education should retain the unique perspectives and thinking styles of science, technology, and mathematics in the design process, which is part of the activity of engineering. In the planning and provision of school education, it is necessary to accurately understand the multi-layered relationship between the design process (repeating the steps Design, Build, and Test) and the unique perspectives and thinking styles of each subject, which are selected and conducted from the context of "need to know" and "need to do for engineering" according to the nature of the subject matter. It can be inferred that designing an appropriate order and combination of the design process (Design, Build, and Test) and the unique perspectives and thinking styles of each subject will lead to fulfilling STEM education lessons.

However, engineering activities such as the design process cannot cover all areas of science, technology, and mathematics learning. Therefore, both education specific to each subject and the idea of interrelated STEM education are necessary.

\section{Discussion}

The framework of STEM education is still being considered in relation to the engineering process and scientific inquiry as it was in the past. To date, the objectives, contents, and activities of science, technology, engineering, and mathematics education have not been clearly positioned. From the perspective of technology education, it is important to consider the positioning of technology in STEM, and it would be useful to generate suggestions for practicing appropriate STEM education. Therefore, in this commentary, based on the principles of subjects in the Japanese curriculum, we proposed a conceptual framework for the appropriate practice of STEM education based on the uniqueness and heterogeneity of science, technology, engineering, and mathematics. 
The proposed conceptual framework mainly refers to the Learning by Design ${ }^{\text {Tw }}$ model in which the processes of "design/redesign" and "investigate and explore" exist in parallel (Kolodner, 2002). We considered engineering, meaning the production of things, processes, systems, etc., in terms of practical STEM activities, and attempted to link it with the principles, perspectives, and thinking styles of science, technology, and mathematics. Specifically, the processes of Design, Build, and Test and the perspectives and thinking styles of each subject were related in a multi-layered manner in the context of "need to do for engineering" and "need to know."

The conceptual framework suggests that STEM education should retain the principles of science, technology, and mathematics in the activity of engineering. This idea is similar to the policy that ITEEA (2018) set out as a principle for the practice and research of STEM education. In other words, in school education, it is necessary to properly understand and grasp the multi-layered relevance of "need to do for engineering" and "need to know" activities and the design process of Design, Build, and Test according to the nature of the subject matter. It can be inferred that the key point for practicing STEM education is to examine and design the appropriate order and combination of the learning process and activities based on the proposed conceptual framework. This conceptual framework can help educational policymakers and architects of STEM education practices to construct an appropriate curriculum that identifies comprehensive STEM concepts and subject principles, particularly in the Japanese context.

From the above, STEM education comprises problemsolving activities related to the design process and scientific inquiry and appropriately utilizes knowledge from each STEM subject, as well as attempting to develop comprehensive and practical skills pertaining to the STEM field. In order to appropriately utilize learning from each subject, it is necessary to grasp the principle of that subject. Therefore, technology education is vital for the appropriate practice and planning of STEM education.

However, the framework proposed in this commentary is only theoretical and cannot yet offer a concrete teaching practice and learning activity. In the future, this limitation may present difficulties when applying this theoretical framework to the real-world characteristics of technology education.

\section{Conclusion}

We proposed a conceptual framework for the appropriate practice of STEM education based on the principles of subjects in the Japanese curriculum. The conceptual framework suggests that the practice of STEM education should retain the principles of science, technology, and mathematics in the activity of engineering. It can be inferred that the key point for practicing STEM education is to examine and design the appropriate order and combination of the learning process and activities based on the proposed conceptual framework. This way of thinking gives STEM education policymakers and curriculum developers a useful perspective for STEM education practice and research. Although this framework is purely theoretical, it can be useful to determine an adequate practice of STEM education and avoid confusion between STEM education and technology education.

\section{Abbreviations}

BSCS: Biological Sciences Curriculum Study; ITEA: International Technology Education Association (changed to ITEEA in 2010); ITEEA: International

Technology and Engineering Educators Association; MEXT: Japanese Ministry of Education, Culture, Sports, Science and Technology; NAEP: National

Assessment of Educational Progress; STEM: Science, technology, engineering, and mathematics

\section{Acknowledgements}

We would like to thank Editage (www.editage.com) for English language editing.

\section{Authors' contributions}

Chikahiko YATA contributed to the composition of the thesis and the analytical interpretation of Japanese subject principles. Tadashi OHTANI was responsible for the analytical interpretation of the engineering definition. Masataka ISOBE contributed to the description of the current status and philosophy of STEM. All authors read and approved the final manuscript.

\section{Funding}

This work was supported by the Japan Society for the Promotion of Science KAKENHI Grant Numbers JP 17H00820, JP 191735.

\section{Availability of data and materials}

All data generated or analyzed during this commentary are included in this published article [and its supplementary information files].

\section{Competing interests}

The authors declare that they have no competing interests.

\section{Author details}

'Department of Technology and Information Education, Graduate School of Education, Hiroshima University, 1-1, Kagamiyama 1-chome, Higashi-, Hiroshima, Japan. ${ }^{2}$ Department of Technology Education, Graduate School of Education, Tokyo Gakugei University, 4-1-1 Nukuikita-machi, Koganei-shi, Tokyo, Japan. ${ }^{3}$ Department of Technology Education, Aichi University of Education, 1 Hirosawa, Igaya-cho, Kariya, Japan.

Received: 17 October 2019 Accepted: 7 February 2020

Published online: 02 March 2020

\section{References}

Banks, F., \& Barlex, D. (2014). Teaching STEM in the secondary school: Helping teachers meet the challenge. Abingdon: Routledge.

Barry, N. B. (2014). 6E Learning byDeSIGN ${ }^{T M}$ model: Maximizing informed design and inquiry in the integrative STEM classroom. The Technology and Engineering Teacher, 68(4), 14-19.

Boakes, N. J. (2019). Cultivating design thinking of middle school girls through an origami STEAM project. Journal for STEM Education Research. https:/doi.org/ 10.1007/s41979-019-00025-8.

Brown, R., Ernst, J., DeLuca, B., \& Kelly, D. (2017). STEM curricula. The Technology and Engineering Teacher, 77(1), 26-29.

Bybee, R. (1997). Achieving scientific literacy: from purpose to practice. Portsmouth: Heinemann.

Bybee, R. (2010). What is STEM education? Science, 329(5995), 996. 
Bybee, R., Taylor, J., et al. (2006). The BSCS 5 E instructional model: origins and effectiveness. Colorado Springs: BSCS.

Committee on STEM Education, National Science and Technology Council. (2013). Federal science, technology, engineering, and mathematics (STEM) education 5-year strategic plan. https://www.whitehouse.gov/sites/ whitehouse.gov/files/ostp/Federal_STEM_Strategic_Plan.pdf. Accessed 2 July 2019.

Cook, K., \& Bush, S. (2018). Design thinking in integrated STEAM learning: Surveying the landscape and exploring exemplars in elementary grades. School Science and Mathematics, 118(4), 93-103.

Daugherty, M. K. (2009). The "T" and "E" in STEM. In ITEEA (Ed.). In The overlooked STEM imperatives: technology and engineering (pp. 18-25). Reston: ITEEA.

Engineering Academy of Japan. (2006). Engineering and social responsibility (in Japanese). https://www.eaj.or.jp/en/wp-content/uploads/sites/2/2017/01/ engineering_shakai.pdf. Accessed 2 July 2019.

Harrison, M. (2011). Supporting the T and the E in STEM: 2004-2010. Design and Technology Education: An International Journal, 16(1), 17-25.

Havice, W. (2009). The power and promise of a STEM education: thriving in a complex technological world. In ITEEA (ed.), The overlooked STEM imperatives: technology and engineering $\mathrm{K}-12$ education (pp. 10-17). Reston: ITEEA.

ITEA. (2000). Standards for technological literacy: Content for study of technology. https://www.iteea.org/File.aspx?id=67767\&v=b26b7852. Accessed 2 July 2019.

ITEA. (2005). Technology for all Americans: A rationale and structure for the study of technology. https://www.iteea.org/file.aspx?id=42633. Accessed 2 July 2019.

ITEEA. (2012). EbD-TEEMS ${ }^{\text {TM }}$ grade 1 agriculture around us. Reston: CD-ROM.

ITEEA. (2015). 6E Learning byDeSIGN ${ }^{\mathrm{TM}}$ : A model for integrated STEM education. https://www.iteea.org/File.aspx?id=116990\&v=e778b404. Accessed 2 July 2019.

ITEEA. (2016). EbD-TEEMS ${ }^{\text {TM }}$ grade 6 our world and me. CD-ROM.

ITEEA. (2018). STEM4: The power of collaboration for change. https://www.iteea. org/File.aspx?id=137271\&v=cb3f06a2. Accessed 13 Nov 2019.

James Dyson Foundation. (2017) What is the design process? Understand the design process and put it into practice. https://www.jamesdysonfoundation. com/content/dam/pdf/Standalone_DesignProcess.pdf\#search=\%27dyson+ What+is+the+design+process $\% 3 \mathrm{~F}+$ Understand+the+design+process+and+ put+into+practice\%27. Accessed 2 July 2019.

Johns, J., \& Mentzer, N. (2016). STEM integration through design and inquiry. The Technology and Engineering Teacher, 76(3), 13-17.

Kelley, T. R., \& Knowles, G. J. (2016). A conceptual framework for integrated STEM education. International Journal of STEM Education, 3(11). https://doi.org/10. 1186/s40594-016-0046-z.

Kolodner, J. L. (2002). Learning by Design ${ }^{\mathrm{TM}}$ : iterations of design challenges for better learning of science skills. Cognitive Studies: Bulletin of the Japanese Cognitive Science Society, 9(3), 338-350.

Malpas, S. R. (2000). The universe of engineering: A UK definition. London: The Royal Academy of Engineering.

McGarr, O., \& Lynch, R. (2017). Monopolising the STEM agenda in second-level schools: Exploring power relations and subject subcultures. International Journal of Technology and Design Education, 27(1), 51-62.

Ministry of Education, Culture, Sports, Science and Technology. (2017). The course of study for lower secondary school. Government of Japan (in Japanese). http://www.mext.go.jp/component/a_menu/education/micro_detail/_ icsFiles/afieldfile/2019/03/18/1413522_002.pdf. Accessed 2 July 2019.

Ministry of Education, Culture, Sports, Science and Technology. (2018a). Explanation for the course of study of technology education for lower secondary school. Government of Japan (in Japanese). http://www.mext.go.jp/ component/a_menu/education/micro_detail/_icsFiles/afieldfile/2019/03/1 8/1387018_009.pdf. Accessed 2 July 2019.

Ministry of Education, Culture, Sports, Science and Technology. (2018b). Explanation for the course of study of science education for lower secondary school. Government of Japan (in Japanese). https://www.mext.go.jp/ component/a_menu/education/micro_detail/_icsFiles/afieldfile/2019/03/1 8/1387018_005.pdf. Accessed 2 July 2019.

Ministry of Education, Culture, Sports, Science and Technology. (2018c). Explanation for the course of study of mathematics education for lower secondary school. Government of Japan (in Japanese). https://www.mext.go. jp/component/a_menu/education/micro_detail/_icsFiles/afieldfile/2019/ 03/18/1387018_004.pdf. Accessed 2 July 2019.
National Academy of Engineering. (2008). Changing the conversation: Messages for improving public understanding of engineering. Washington, D.C: The National Academies Press.

National Assessment Governing Board. (2013). Technology and engineering literacy framework for the 2014 National Assessment of Educational Progress. https://www.nagb.gov/content/nagb/assets/documents/publications/ frameworks/technology/2014-technology-framework.pdf. Accessed 2 July 2019.

Reed, P. A. (2018). Reflections on STEM, standards, and disciplinary focus. The Technology and Engineering Teacher, 77(7), 16-20.

Review Committee on Educational Programs in Engineering. (1998). Examination of educational programs in engineering centered on the engineering department of 8 universities (in Japanese). https://www.eng.hokudai.ac.jp/ jeep/08-10/pdf/pamph01.pdf. Accessed 13 Nov 2019.

Ritz, J. R., \& Fan, S.-C. (2015). STEM and technology education: international stateof-the-art. International Journal of Technology and Design Education, 25(4), $429-451$.

Royal Society. (2016). Making education your business. https://royalsociety.org/ topics-policy/publications/2016/making-education-your-business/. Accessed 2 July 2019.

Sanders, M. (2009). Integrative STEM education: Primer. Technology Teacher, 68(4), 20-26.

Successful STEM Education. (2013) Engineering: Emphasizing the "E" in STEM education. http://www.successfulstemeducation.org/sites/default/files/ STEM\%20Smart\%20Engineering\%20Brief\%20final_0.pdf. Accessed 13 Nov 2019.

Wells, J. (2016). PIRPOSAL model of integrative STEM education: Conceptual and pedagogical framework for classroom implementation. Technology and Engineering Teacher, 75(6), 12-19.

\section{Publisher's Note}

Springer Nature remains neutral with regard to jurisdictional claims in published maps and institutional affiliations.

\section{Submit your manuscript to a SpringerOpen ${ }^{\circ}$ journal and benefit from:}

- Convenient online submission

- Rigorous peer review

- Open access: articles freely available online

- High visibility within the field

- Retaining the copyright to your article

Submit your next manuscript at $\boldsymbol{\nabla}$ springeropen.com 